\title{
Survey of spatial distribution of vector-borne disease in neighborhood dogs in southern Brazil
}

\author{
Caroline Constantino ${ }^{1}$, Edson Ferraz Evaristo de Paula ${ }^{2}$, Ana Pérola Drulla Brandão ${ }^{3}$, Fernando Ferreira ${ }^{3}$, Rafael \\ Felipe da Costa Vieira ${ }^{1}$ and Alexander Welker Biondo ${ }^{1,2^{*}}$ \\ ${ }^{I}$ Department of Veterinary Medicine, Federal University of Paraná, Curitiba, PR, 80035-050, Brazil \\ ${ }^{2}$ Animal Protection Section, City Secretary of Environment, Curitiba, PR, 80020-290, Brazil \\ 3Department of Preventive Veterinary Medicine, University of São Paulo, São Paulo, SP, 05508-270, Brazil
}

\begin{abstract}
Neighborhood dogs may act as reservoirs and disseminators of vector-borne diseases in urban areas. Accordingly, the aim of this study was to ascertain the health status and the vector-borne pathogens infecting dogs living in public areas with high levels of human movement in the city of Curitiba, southern Brazil. Blood samples from 21 neighborhood dogs that were found in nine of 22 bus stations and two public parks were subjected to a complete blood cell (CBC) count, serum biochemical profiling, a commercial rapid ELISA test and a commercial real-time PCR panel of vectorborne diseases. The CBC count and serum biochemical profiling were within the normal range for dogs and only $1 / 21$ (4.7\%) of the dogs was seroreactive for Borrelia burgdorferi sensu stricto. The commercial real-time PCR panel showed that 7/21 (33.3\%) of the dogs had Mycoplasma haemocanis infection, 9/21 (42.8\%) had 'Candidatus Mycoplasma haematoparvum' and 4/21 (19.0\%) had both. No statistical association between infected by the agents found here and abnormalities in physical examinations, laboratory tests or ectoparasite presence was found $(p>0.05)$. In conclusion, neighborhood dogs showed low prevalence of vector-borne diseases and satisfactory wellbeing, and dogs can be used as sentinels for disease exposure.
\end{abstract}

Keywords: Borrelia burgdorferi, Community dogs, Hemoplasmas, Sentinel animals, Tick-borne diseases.

\section{Introduction}

Dogs have been indicated as potential public health sentinels because of their close interaction with humans, particularly their owners, while presenting associations with common infectious agents and vectors (Backer et al., 2001; Schmidt, 2009; Schurer et al., 2012).

Whereas true sentinels should reveal diseases without harboring them, dogs may become reservoirs for certain diseases such as visceral leishmaniasis (DantasTorres, 2009).

Moreover, dogs may act as potential sources of dissemination of invertebrate vectors and transmission of their zoonoses (Schmidt, 2009).

Although neighborhood dogs have been defined for more than two decades as semi-restricted or free-range animals with semi-dependence on one or more families for food and shelter (WHO/WSPA, 1990), their health status and role in maintaining and spreading zoonotic diseases has yet to be fully established.

In addition, dogs that lack healthcare such as regular vaccination, deworming, and ectoparasite control may have greater susceptibility to diseases and/or environmental bioaccumulation as well as negatively impact animal welfare (Salb et al., 2008).
Owned dogs in southern Brazil have been shown to have higher exposure to tick-borne pathogens in urban areas than in rural settings (Vieira et al., 2013b).

Moreover, dogs may serve as a potential source for transmission of canine vector-borne diseases (CVBDs) with zoonotic risk (Diniz et al., 2007; Otranto et al., 2009a, 2009b; Vieira et al., 2013a; Eremeeva and Dasch, 2015). Within this scenario, neighborhood dogs can be expected to be at higher risk of infection because of their urban roaming and vector exposure. The city of Curitiba, the capital of the state of Paraná, is currently the eighth biggest city and the ninth biggest metropolitan area in Brazil, with approximately 3.5 million habitants (IBGE, 2014).

Although commonly found in low-income neighborhoods of urban areas, neighborhood dogs may find sufficient food and shelter in bus stations because of the infrastructure and high levels of human movement. Since the city of Curitiba has no subway, 1.1 million daily users rely on ground transportation interconnected by 22 main bus stations. Accordingly, the aim of the present study was to survey CVBDs in neighborhood dogs found in public areas with high daily levels of human movement (bus stations and public parks) in the city of Curitiba, southern Brazil. 


\section{Materials and Methods}

The present study was approved by the Ethics Committee for Animal Experimentation and Animal Welfare of the Federal University of Paraná, state of Paraná, southern Brazil (protocol number 027/2015).

\section{Cross-sectional study and sampling}

All 22 bus stations and two public parks in the city of Curitiba ( $25^{\circ} 25^{\prime} 40^{\prime \prime} \mathrm{S}$ and $\left.49^{\circ} 16^{\prime} 23^{\prime \prime} \mathrm{W}\right)$, in southern Brazil, were included in this study (Fig. 1).

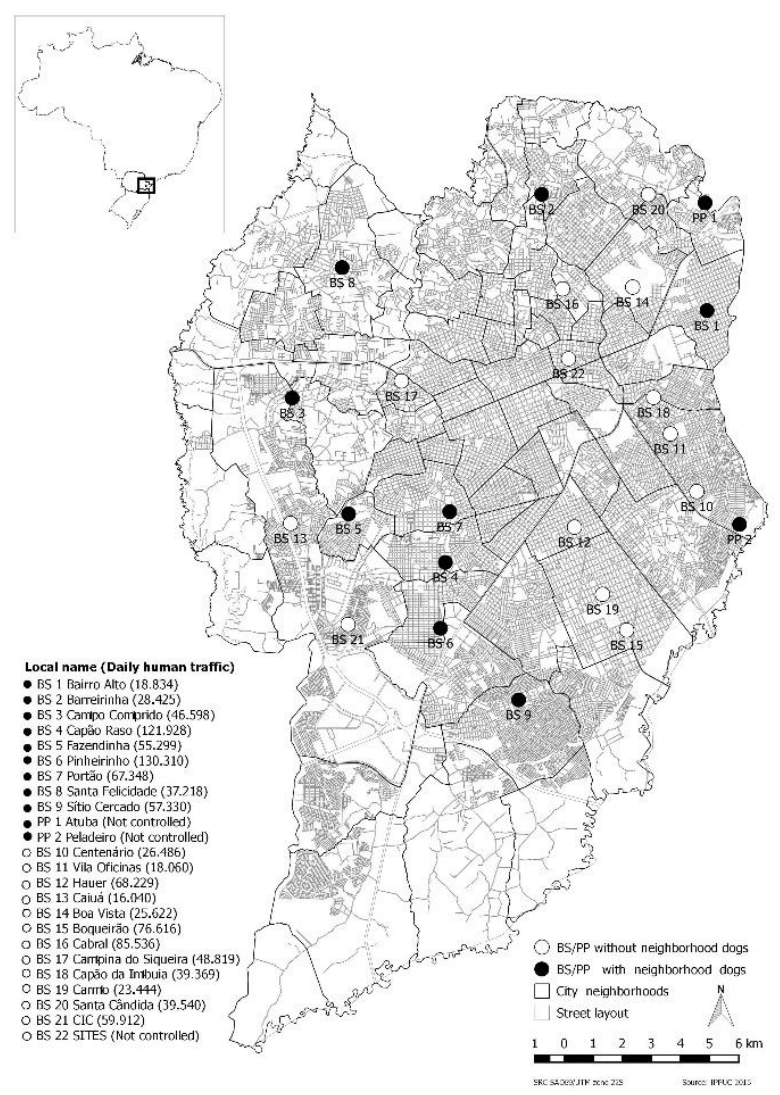

Fig. 1. Map of Brazil showing the locations of the state of Paraná and city of Curitiba. Enlarged map shows locations and daily human movements of the bus stations (BS) and public parks (PP) included in the study, distinguishing those at which neighborhood dogs were sampled. City of Curitiba, state of Paraná, Brazil, 2016.

At the time of the survey, the city of Curitiba had an estimated population of $1,864,416$ inhabitants distributed over an area of $435,036 \mathrm{~km}^{2}$, located at 934.6 meters above sea level. This city has humid subtropical climate, with rainfall of $1,434 \mathrm{~mm} /$ year and average winter and summer temperatures of $10{ }^{\circ} \mathrm{C}$ and $22{ }^{\circ} \mathrm{C}$ respectively (IBGE, 2014).

The dog inclusion criteria were applied in accordance with the World Health Organization (WHO) definition of neighborhood dogs (WHO/WSPA, 1990), as follows: semi-restricted or entirely free to wander and establish food and shelter dependency with users and workers at the bus stations and parks. A total of 21 neighborhood dogs, 19 from 9/22 bus stations (40.9\% of the bus stations) and two from each public park, were found between February and April of 2014 (Fig. 1). The dogs were all of mixed breed and aged $\geq 1$ year; $8 / 21$ $(38.1 \%)$ were females and 13/21 (61.9\%) were males. They were physically restrained and underwent physical examination. Since over 1.0 million people daily use the ground transportation of Curitiba, researchers were allowed by the City Secretary of Transportation to perform capture, physical restrain and dog samplings on site only between February and April (mild Autumn). Blood samples were collected by means of venipuncture of the jugular vein using commercial sterile vacuum tubes with and without EDTA. Thereafter, complete blood cell (CBC) counts and biochemical profiling were performed, and the remaining aliquots were stored at $-20{ }^{\circ} \mathrm{C}$ for further molecular and serological analysis.

\section{Laboratory tests}

$\mathrm{CBC}$ counts and biochemical profiling were performed on all samples. $\mathrm{CBC}$ counts were performed in a commercial automated hematological analyzer (CC550, Celm Ltd, São Paulo, Brazil). Blood smears were made from fresh blood samples; they were dried and stained using a commercial staining agent (Diff-Quick; Panótico Rápido LB, Laborclin, São Paulo, Brazil), and differential leukocyte counts and cell morphology analysis were performed under an optical microscope. Alanine aminotransferase (ALT) and alkaline phosphatase (ALP) activity levels and creatinine concentrations were determined by means of the kinetic method, urea concentrations by means of the enzymatic method and total protein and fractions by means of the colorimetric method, using a commercial semiautomatic analyzer (Bio-20001L, Bioplus, São Paulo, Brazil).

Serum samples were tested for Dirofilaria immitis, Ehrlichia spp. (E. canis, E. chaffeensis and E. ewingii), Borrelia burgdorferi sensu stricto (s.s.) and Anaplasma spp. (A. phagocytophilum and A. platys) using a commercial rapid ELISA test $\left(\mathrm{SNAP}^{\circledR} 4 \mathrm{Dx}^{\circledR}\right.$ Plus, IDEXX Laboratories Inc., Westbrook, ME, USA), in accordance with the manufacturer's instructions.

Whole EDTA-blood samples were tested for Babesia spp., Anaplasma spp., Ehrlichia spp., Rickettsia spp., Hepatozoon spp., Leishmania spp., Neorickettsia risticii, Bartonella spp., Mycoplasma haemocanis and 'Candidatus Mycoplasma haematoparvum', using a commercial real-time PCR panel of vector-borne diseases (IDEXX Laboratories, Westbrook, ME, USA). DNA was extracted from the blood samples using standard protocols on a commercial platform (Corbett XTractor-Gene, Qiagen, Valencia, CA, USA). A housekeeping gene (18S rRNA) was used to determine DNA content and quality. The primers for both the 
housekeeping gene and the PCR test were based on IDEXX's proprietary real-time PCR oligonucleotides (IDEXX Laboratories). Real-time PCR was performed using default-cycling conditions in commercial apparatus (Roche LC480 in the 384-well plate configuration, Roche Applied Science, Indianapolis, IN, USA).

\section{Statistical analysis}

The data were stored in electronic spreadsheets (Microsoft Excel $^{\circledR}$ 2010) and subsequently analyzed using the SPSS (2008) statistical software (version 17.0). Descriptive analyses with frequency distributions were performed and in order to verify bivariate associations, nonparametric Fisher's exact tests were conducted, at the 5\% significance level. In addition, to measure the relationship between daily human movement and the number of neighborhood dogs in the study locations, the Pearson correlation coefficient was calculated.

\section{Results and Discussion}

All 21 neighborhood dogs were considered to be clinically healthy and had CBC counts and biochemical profiles within the normal range for the species. Only $1 / 21(4.8 \%)$ of the dogs was seroreactive for Borrelia burgdorferi s.s. according to the commercial rapid ELISA test. The commercial real-time PCR panel revealed that $7 / 21(33.3 \%)$ of the dogs were positive for M. haemocanis, 9/21 (42.8\%) for ' $\mathrm{Ca}$. M. haematoparvum' and 4/21 (19\%) for both (Table 1). All 21 neighborhood dogs tested negative for the remaining CVBDs according to both real-time PCR and the rapid ELISA test.

No significant association was found between gender $(p=0.337)$ or presence of ectoparasites $(p=0.638)$ and infection by $M$. haemocanis, or between gender ( $p=$ $0.642)$ or presence of ectoparasites $(p=0.642)$ and infection by ' $\mathrm{Ca}$. M. haematoparvum'. The number of neighborhood dogs did not show any correlation with the daily human movement at the bus stations (Pearson correlation coefficient $=0.347, p=0.123$ ).

In this cross-sectional study, neighborhood dogs were screened for CVBDs by means of serological and molecular methods. Despite the WHO definition published 25 years ago, this was the first study to survey health status and CVBDs in neighborhood dogs, to the best of the authors' knowledge. Since these dogs may have spent their time continuously roaming outdoors, their exposure to vectors and pathogens was expected to be relatively higher than that of owned dogs (Azzag et al., 2015). Surprisingly, despite lacking traditional ownership, these dogs were found to be healthy on clinical examination, with $\mathrm{CBC}$ counts and biochemical profiles within the normal range, and they mostly tested negative for CVBD. In Brazil, previous studies have shown that the prevalence of CVBDs in dogs in urban areas has varied from absence to $91.2 \%$
(Lasta et al., 2013; Spolidorio et al., 2013; Vieira et al., $2013 \mathrm{~b}$ ). Although the neighborhood dogs of the present study had comparatively lower CVBD prevalence (Vieira et al., 2013b; Azzag et al., 2015), the wide differences in CVBD prevalence may be explained by the populations studied, lifestyles, environmental occurrence of vectors and diseases, diagnostic tests used and vector competence of ticks from the Rhipicephalus sanguineus group (Balakrishnan et al., 2014; Maia et al., 2015; Moraes-Filho et al., 2015).

As observed here, infection by CVBDs may occur in the absence of clinical signs (Joppert et al., 2001; Maggi et al., 2014; Azzag et al., 2015) or hematological changes (Novacco et al., 2010; Balakrishnan et al., 2014; Moraes-Filho et al., 2015). A previous study on owned dogs did not show any significant associations between hemoplasma infection and anemia, ectoparasite infestation, gender and clinical status (Tennant et al., 2011), thus corroborating the findings from the neighborhood dogs of the present study.

Although neighborhood dogs with outdoor lives in urban areas may be at higher risk of exposure to tickborne pathogens (Cardoso et al., 2012; Vieira et al., 2013b; Maia et al., 2015), only 1/7 (14.3\%) of the dogs infected by $M$. haemocanis and $1 / 9(11.1 \%)$ by ' $\mathrm{Ca}$. M. haematoparvum' were infested by ticks. No association was found between the presence of ectoparasites and positivity for at least one species of Mycoplasma ( $p=$ 0.397). Although Mycoplasma spp. infection has previously been reported in dogs (Ramos et al., 2010; Valle et al., 2014; Vieira et al., 2015) and has been correlated with exposure to ticks and fleas in Brazil (Valle et al., 2014), our findings corroborate other reports from Brazil, Greece and Africa, which did not find any association between hemoplasma infection and ticks (Barker et al., 2010; Tennant et al., 2011; Vieira et al., 2015). Since the clinical examinations were limited to the time of sampling, it is possible that these dogs may have acquired and eliminated ticks before this time.

Despite the low prevalence of $M$. haemocanis and ' $C a$. M. haematoparvum' hemoplasmas in the neighborhood dogs, these pathogens have previously been reported infecting humans (Kallick, 2010; Maggi et al., 2013a, $2013 b)$. Since neighborhood dogs may play a role as environmental CVBD reservoirs and/or disseminators, zoonotic potential should always be considered, particularly because of these animals' close contact with users at bus stations every day. Thus, these animals should be continuously monitored as environmental sentinels for hemoplasmas and other CVBDs. Although seropositivity has been already reported in dogs, human beings and horses in Brazil, no molecular evidence of $B$. burgdorferi infection has been found to date (Joppert et al., 2001; Labarthe et al., 2003; Spolidorio et al., 2010; Montandon et al., 2014). 
Table 1. Location and results of molecular and serological tests performed on blood samples from 21 neighborhood dogs in the city of Curitiba, state of Paraná, Brazil, 2016.

\begin{tabular}{|c|c|c|c|c|c|c|c|}
\hline \multirow{2}{*}{\multicolumn{2}{|c|}{ Neighborhood dog }} & \multicolumn{4}{|c|}{ Commercial real-time PCR panel of vector-borne diseases } & \multirow{2}{*}{\multicolumn{2}{|c|}{$\begin{array}{c}\text { Commercial rapid ELISA test } \\
\text { Borrelia burgdorferi }\end{array}$}} \\
\hline & & \multicolumn{2}{|c|}{ M. haemocanis } & \multicolumn{2}{|c|}{ 'Ca. M. haematoparvum' } & & \\
\hline Location & Number & Positive $(\%)$ & Negative (\%) & Positive (\%) & Negative (\%) & Positive $(\%)$ & Negative (\%) \\
\hline BS 1 & 1 & $0 / 1(0)$ & $1 / 1(100)$ & $1 / 1(100)$ & $0 / 1(0)$ & $0 / 1(0)$ & $1 / 1(100)$ \\
\hline BS 2 & 5 & $1 / 5(20)$ & $4 / 5(80)$ & $1 / 5(20)$ & $4 / 5(80)$ & $0 / 5(0)$ & $5 / 5(100)$ \\
\hline BS 3 & 1 & $0 / 1(0)$ & $1 / 1(100)$ & $0 / 1(0)$ & $1 / 1(100)$ & $0 / 1(0)$ & $1 / 1(100)$ \\
\hline BS 4 & 1 & $1 / 1(100)$ & $0 / 1(0)$ & $1 / 1(100)$ & $0 / 1(0)$ & $0 / 1(0)$ & $1 / 1(100)$ \\
\hline BS 5 & 2 & $1 / 2(50)$ & $1 / 2(50)$ & $2 / 2(100)$ & $0 / 2(0)$ & $0 / 2(0)$ & $2 / 2(100)$ \\
\hline BS 6 & 5 & $2 / 5(40)$ & $3 / 5(60)$ & $1 / 5(20)$ & $4 / 5(80)$ & $0 / 5(0)$ & $5 / 5(100)$ \\
\hline BS 7 & 2 & $0 / 2(0)$ & $2 / 2(100)$ & $2 / 2(100)$ & $0 / 2(0)$ & $1 / 2(50)$ & $1 / 2(50)$ \\
\hline BS 8 & 1 & $0 / 1(0)$ & $1 / 1(100)$ & $0 / 1(0)$ & $1 / 1(100)$ & $0 / 1(0)$ & $1 / 1(50)$ \\
\hline BS 9 & 1 & $1 / 1(100)$ & $0 / 1(0)$ & $0 / 1(0)$ & $1 / 1(100)$ & $0 / 1(0)$ & $1 / 1(50)$ \\
\hline PP 1 & 1 & $0 / 1(0)$ & $1 / 1(100)$ & $0 / 1(0)$ & $1 / 1(100)$ & $0 / 1(0)$ & $1 / 1(50)$ \\
\hline PP 2 & 1 & $1 / 1(100)$ & $0 / 1(0)$ & $1 / 1(100)$ & $0 / 1(0)$ & $0 / 1(0)$ & $1 / 1(50)$ \\
\hline Total & 21 & $7 / 21(33.3)$ & $14 / 21(66.6)$ & 9/21 (42.8) & $12 / 21(57.1)$ & $1 / 21(4.8)$ & $20 / 21(95.2)$ \\
\hline
\end{tabular}

(BS): Bus station; (PP): Public park.

Thus, the finding of a neighborhood dog that was seropositive for $B$. burgdorferi in the present study may have potentially been a false positive. This result may have been due to the high sensitivity $(94.1 \%)$ and good specificity $(96.2 \%)$ for specific antibodies to the C6 synthetic peptide to $B$. burgdorferi s.s. presented by the commercial rapid ELISA test used here.

Alternatively, our findings may have been the consequence of a low tick infection rate (Spolidorio et al., 2010) or a conceivably different $B$. burgdorferi strain or a similar species in Brazil (Joppert et al., 2001; Montandon et al., 2014). Nonetheless, further studies should be conducted in order to fully establish the potential association between antibody presence and the zoonotic Brazilian Baggio-Yoshinari syndrome.

Since direct transfer of infected ticks between dogs and human beings is considered to be a minor transmission factor (Goossens et al., 2001), dogs may not be important pathogen disseminators. As previously shown, dogs may be suitable sentinels for evaluating the environmental risk of human exposure to $B$. burgdorferi (Duncan et al., 2005). Moreover, since dogs may be more exposed to ticks, particularly in endemic areas, monitoring of anti- $B$. burgdorferi antibodies in neighborhood dogs may indicate an environmental risk of human exposure.
Despite relatively low number of individuals, the neighborhood dogs in the present study were randomly distributed throughout the city (Fig. 1). In addition, a high degree of result repetition was observed since all the dogs were considered to have adequate health status and were within the normal ranges for the $\mathrm{CBC}$ count and biochemical profile for the species, with low prevalence of CVBD.

No previous survey has been found to date on tested pathogens (Dirofilaria immitis, Ehrlichia canis, E. chaffeensis, E. ewingii, Borrelia burgdorferi sensu stricto, Anaplasma phagocytophilum, A. platys, Babesia spp., Rickettsia spp., Hepatozoon spp., Leishmania spp., Neorickettsia risticii, Bartonella spp., Mycoplasma haemocanis and 'Candidatus Mycoplasma haematoparvum') in human samples at the city of Curitiba or surrounding areas. AntiEhrlichia spp. antibodies in human samples were reported in a rural settlement of northern Paraná state, however without molecular evidence of infection (Vieira et al., 2015). Also within the Paraná state, the first detection of antibodies against B. burgdorferi sensu latu was reported in human beings living in the same rural area (Gonçalves et al., 2013).

Finally, the adequate clinical and laboratory health status observed among these neighborhood dogs may 
imply that these dogs in the city of Curitiba were living under good animal sanitary and welfare conditions, particularly since some of the bus stations have a human movement of over than 100,000 daily users (Fig. 1). Furthermore, since these neighborhood dogs were receiving water, food and shelter at the bus stations, their individual $\mathrm{CBC}$ counts and clinical biochemical profiles together may indicate that they were in a situation of animal welfare in an overall nonharmful environment. The low prevalence of CVBD among these neighborhood dogs may show that was a low environmental risk and consequently a low risk of dissemination, particularly in the bus stations. Moreover, clinically healthy dogs with CBC counts and biochemical profiles within the normal range may represent a state of low environmental toxicity and satisfactory animal welfare. In conclusion, neighborhood dogs should be continuously monitored and may act as sentinels for environmental risk such as vector-borne diseases in public areas with highly human movement.

\section{Acknowledgements}

We thank Aline Gizzi, Cynthia Silva, Camila Martins and the staff of the Animal Service of city of Curitiba for their in-field assistance. We thank the Araucaria Support Foundation for Scientific and Technological Development of the State of Paraná for the full financial support (grant number 292/13) for this research and the Coordination Office for Improvement of HigherEducation Personnel for the master's fellowship.

\section{Conflict of Interest}

The authors declare that no competing interests exist.

\section{References}

Azzag, N., Petit, E., Gandoin, C., Bouillin, C., Ghalmi, F., Haddad, N. and Boulouis, H.J. 2015. Prevalence of select vector-borne pathogens in stray andclientowned dogs from Algiers. Comp. Immunol. Microbiol. Infect. Dis. 38, 1-7.

Backer, L.C., Grindem, C.B., Corbett, W.T., Cullins, L. and Hunter, J.L. 2001. Pet dogs as sentinels for environmental contamination. Sci. Total Environ. 274, 161-169.

Balakrishnan, N., Musulin, S., Varanat, M., Bradley, J.M. and Breitschwerdt, E.B. 2014. Serological and molecular prevalence of selected canine vector borne pathogens in blood donor candidates, clinically healthy volunteers, and stray dogs in North Carolina. Parasit. Vectors 7, 116-125.

Barker, E.N, Tasker, S., Day, M.J., Warman, S.M., Woolley, K., Birtles, R., Georges, K.C., Ezeokoli, C.D., Newaj-Fyzul, A., Campbell, M.D., Sparagano, O.A., Cleaveland, S. and Helps, C.R. 2010. Development and use of real-time PCR to detect and quantify Mycoplasma haemocanis and
"Candidatus Mycoplasma haematoparvum" in dogs. Vet. Microbiol. 140, 167-170.

Cardoso, L., Mendão, C. and de Carvalho, L.M. 2012. Prevalence of Dirofilaria immitis, Ehrlichia canis, Borrelia burgdorferi sensu lato, Anaplasma spp. and Leishmania infantum in apparently healthy and CVBD-suspect dogs in Portugal-a national serological study. Parasit. Vectors 5, 62-71.

Dantas-Torres, F. 2009. Canine leishmaniosis in South America. Parasit. Vectors 2, S1.

Diniz, P.P., Schwartz, D.S., de Morais, H.A. and Breitschwerdt, E.B. 2007. Surveillance for zoonotic vector-borne infections using sick dogs from southeastern Brazil. Vector Borne Zoonotic Dis. 7, 689-697.

Duncan, A.W., Correa, M.T., Levine, J.F. and Breitschwerdt, E.B. 2005. The dog as a sentinel for human infection: prevalence of Borrelia burgdorferi C6 antibodies in dogs from southeastern and mid-Atlantic States. Vector Borne Zoonotic Dis. 5, 101-109.

Eremeeva, M.E. and Dasch, G.A. 2015. Challenges posed by tick-borne rickettsiae: eco-epidemiology and public health implications. Front. Public Health 3, 55-72.

Gonçalves, D.D., Benitez, A., Lopes-Mori, F.M.R., Alves, L.A., Freire, R.L., Navarro, I.T., Santana, M.A.Z., Santos, L.R.A., Carreira, T., Vieira, M. L. and Freitas, J.C.D. 2013. Zoonoses in humans from small rural properties in Jataizinho, Parana, Brazil. Brazilian J. Microbiol. 44, 125-131.

Goossens, H.A., Van Den Bogaard, A.E. and Nohlmans, M.K. 2001. Dogs as sentinels for human Lyme borreliosis in The Netherlands. J. Clin. Microbiol. 39, 844-848.

IBGE. 2014. Instituto Brasileiro de Geografia e Estatística. Estimativas da População dos Municípios Brasileiros com Data de Referência em $1^{\circ}$ de Julho de 2014 http://www.ibge.gov.br/home/presidencia/noticias/ pdf/analise_estimativas_2014.pdf (Accessed on 05 may 2015).

Joppert, A.M., Hagiwara, M.K. and Yoshinari, N.H. 2001. Borrelia burgdorferi antibodies in dogs from Cotia county, São Paulo State, Brazil. Rev. Inst. Med. Trop. São Paulo 43, 251-255.

Kallick, C.A. 2010. Specific bacterial inclusions in bone marrow cells indicate systematic lupus erythematosus, and treatment for lupus. U.S. Patent 7, 820, 405.

Labarthe, N., Pereira, M.C., Barbarini, O., McKee, W., Coimbra, C.A. and Hoskins, J. 2003. Serologic prevalence of Dirofilaria immitis, Ehrlichia canis, and Borrelia burgdorferi infections in Brazil. Vet. Ther. 4, 67-75. 
Lasta, C.S., Santos, A.P., Messick, J.B., Oliveira, S.T., Biondo, A.W., Vieira, R.F., Dalmolin, M.L. and González, F.H. 2013. Molecular detection of Ehrlichia canis and Anaplasma platys in dogs in Southern Brazil. Rev. Bras. Parasitol. Vet. 22, 360366.

Maggi, R.G., Birkenheuer, A.J., Hegarty, B.C., Bradley, J.M., Levy, M.G. and Breitschwerdt, E.B. 2014. Comparison of serological and molecular panels for diagnosis of vector-borne diseases in dogs. Parasit. Vectors 7, 127-136.

Maggi, R.G., Compton, S.M., Trull, C.L., Mascarelli, P.E., Mozayeni, B.R. and Breitschwerdt, E.B. 2013b. Infection with Hemotropic Mycoplasma Species in Patients with or without Extensive Arthropod or Animal Contact. J. Clin. Microbiol. 51, 3237-3241.

Maggi, R.G., Mascarelli, P.E., Havenga, L.N., Naidoo, V. and Breitschwerdt, E.B. 2013a. Co-infection with Anaplasma platys, Bartonella henselae and Candidatus Mycoplasma haematoparvum in a veterinarian. Parasit. Vectors 6, 103-113.

Maia, C., Almeida, B., Coimbra, M., Fernandes, M.C., Cristóvão, J.M., Ramos, C., Martins, Â., Martinho, F., Silva, P., Neves, N., Nunes, M., Vieira, M.L., Cardoso, L. and Campino, L. 2015. Bacterial and protozoal agents of canine vector-borne diseases in the blood of domestic and stray dogs from southern Portugal. Parasit. Vectors 23, 138-145.

Montandon, C.E., Yoshinari, N.H., Milagres, B.S., Mazioli, R., Gomes, G.G., Moreira, H.N., Padilha, A.F., Wanderley, G.G., Mantovani, E., Galvão, M.A., Langoni, H. and Mafra, C. 2014. Evidence of Borrelia in wild and domestic mammals from the state of Minas Gerais, Brazil. Rev. Bras. Parasitol. Vet. 23, 287-290.

Moraes-Filho, J., Krawczak, F.S., Costa, F.B., Soares, J.F. and Labruna, M.B. 2015. Comparative Evaluation of the Vector Competence of Four South American Populations of the Rhipicephalus sanguineus Group for the Bacterium Ehrlichia canis, the Agent of Canine Monocytic Ehrlichiosis. PLoS One 10, 1-16.

Novacco, M., Meli, M.L., Gentilini, F., Marsilio, F., Ceci, C., Pennisi, M.G., Lombardo, G., Lloret, A., Santos, L., Carrapiço, T., Willi, B., Wolf, G., Lutz, H. and Hofmann-Lehmann, R. 2010. Prevalence and geographical distribution of canine hemotropic mycoplasma infections in Mediterranean countries and analysis of risk factors for infection. Vet. Microbiol. 142, 276-284.

Otranto, D., Dantas-Torres, F. and Breitschwerdt, E.B. 2009a. Managing canine vector-borne diseases of zoonotic concern: part one. Trends Parasitol. 25, 157-163.
Otranto, D., Dantas-Torres, F. and Breitschwerdt, E.B. 2009b. Managing canine vector-borne diseases of zoonotic concern: part two. Trends Parasitol. 25, 228-235.

Ramos, R., Ramos, C., Araújo, F., Oliveira, R., Souza, I., Pimentel, D., Galindo, M., Santana, M., Rosas, E., Faustino, M. and Alves, L. 2010. Molecular survey and genetic characterization of tick-borne pathogens in dogs in metropolitan Recife (northeastern Brazil). Parasitol. Res. 107, 1115-1120.

Salb, A.L., Barkema, H.W., Elkin, B.T., Thompson, R.C., Whiteside, D.P., Black, S.R., Dubey, J.P. and Kutz, S.J. 2008. Dogs as sources and sentinels of parasites in humans and wildlife, northern Canada. Emerg. Infect. Dis. 14, 60-63.

Schmidt, P.L. 2009. Companion animals as sentinels for public health. Vet. Clin. North Am. Small Anim. Pract. 39, 241-250.

Schurer, J.M., Hill, J.E., Fernando, C. and Jenkins, E.J. 2012. Sentinel surveillance for zoonotic parasites in companion animals in indigenous communities of Saskatchewan. Am. J. Trop. Med. Hyg. 87, 495498.

Spolidorio, M.G., Labruna, M.B., Machado, R.Z., Moraes-Filho, J., Zago, A.M., Donatele, D.M., Pinheiro, S.R. Silveira, I., Caliari, K.M. and Yoshinari, N.H. 2010. Survey for tick-borne zoonoses in the State of Espirito Santo, Southeastern Brazil. Am. J. Trop. Med. Hyg. 83, 201-206.

Spolidorio, M.G., Minervino, A.H., Valadas, S.Y., Soares, H.S., Neves, K.A., Labruna, M.B., Ribeiro, M.F. and Gennari, S.M. 2013. Serosurvey for tickborne diseases in dogs from the Eastern Amazon, Brazil. Rev. Bras. Parasitol. Vet. 22, 214-219.

SPSS Inc. Released 2008. SPSS Statistics for Windows, Version 17.0. Chicago: SPSS Inc.

Tennant, K.V., Barker, E.N., Polizopoulou, Z., Helps, C.R. and Tasker, S. 2011. Real-time quantitative polymerase chain reaction detection of haemoplasmas in healthy and unhealthy dogs from Central Macedonia, Greece. J. Small Anim. Pract. 52, 645-649.

Valle, S.F., Messick, J.B., dos Santos, A.P., Kreutz, L.C., Duda, N.C., Machado, G., Corbellini, L.G., Biondo, A.W. and González, F.H. 2014. Identification, occurrence and clinical findings of canine hemoplasmas in southern Brazil. Comp. Immunol. Microbiol. Infect. Dis. 37, 259-265.

Vieira, R.F., Vieira, T.S., Nascimento, D.A., Martins, T.F., Krawczak, F.S., Labruna, M.B., Chandrashekar, R., Marcondes, M., Biondo, A.W. and Vidotto, O. 2013a. Serological survey of Ehrlichia species in dogs, horses and humans: zoonotic scenery in a rural settlement from southern 
Brazil. Rev. Inst. Med. Trop. São Paulo 55, 335340.

Vieira, R.F., Vidotto, O., Vieira, T.S., Guimarães, A.M., Santos, A.P., Nascimento, N.C., Santos, N.J., Martins, T.F., Labruna, M.B., Marcondes, M., Biondo, W.B. and Messick, J.B. 2015. Molecular investigation of hemotropic mycoplasmas in human beings, dogs and horses in a rural settlement in southern Brazil. Rev. Inst. Med. Trop. São Paulo 57, 353-357.
Vieira, T.S., Vieira, R.F., Nascimento, D.A., Tamekuni, K., Toledo, R.S., Chandrashekar, R., Marcondes, M., Biondo, A.W. and Vidotto, O. 2013b. Serosurvey of tick-borne pathogens in dogs from urban and rural areas from Parana State, Brazil. Rev. Bras. Parasitol. Vet. 22, 104-109.

WHO/WSPA. 1990. World Health Organization/ World Society for the Protection of Animals. Guidelines for dog population management. World Health Organization, Geneva. 